\title{
ESCOLA SEM PARTIDO E A VISÃO DISTORCIDA DE EDUCAÇÃO' ${ }^{1}$
}

\section{SCHOOL WITHOUT PARTY AND THE DISTORTED VIEW ABOUT EDUCATION}

\author{
Walace Ferreira* \\ Alberto Alvadia Filho**
}

\begin{abstract}
Resumo: Este trabalho analisa como o programa Escola Sem Partido (ESP), considerando tanto suas forças enquanto movimento de ordem conservadora quanto suas propostas de lei, trabalha com um projeto distorcido de educação. O ESP trata de valores como moral, ética, laicidade e liberdade no âmbito da pluralidade, quando, na verdade, supõe a supressão da pluralidade em favor de um ensino que se pretende estéril e unidimensional, estimulando o denuncismo, o controle e o cultivo a valores nocivos pedagogicamente. Ademais, defende uma escola reduzida aos valores do consumo, rejeitando a perspectiva educacional calcada na reflexão e na crítica estimulada especialmente pelas disciplinas de humanidades.
\end{abstract}

Palavras-chaves: Escola sem Partido. Educação. Conservadorismo.

Abstract: This paper analyzes how the School Without Party (SWP), considering both its forces as a conservative movement and its proposals for law, work with a distorted education project. School Without Party deals with values such as morality, ethics, secularism and freedom in the context of plurality, when, in fact, it supposes the suppression of plurality in favor of a sterile and unidimensional teaching, stimulating denunciation, control and cultivation to values which are pedagogically harmful. In addition also defends a school reduced to the values of the consumption, rejecting the educational perspective based on the reflection and the critic stimulated especially by the disciplines of humanities.

Keywords: School without party movement. Education. Conservatism.

\footnotetext{
${ }^{1}$ Trabalho preparado para apresentação no "Seminário Direitos Humanos em Perspectiva" promovido pelo Centro Cultural da Justiça Federal e realizado entre os dias 19 e 21 de setembro de 2018. Tratase de artigo adaptado em relação à versão publicada por ambos os autores na Revista e-Mosaicos, intitulado "A serpente pedagógica: O projeto Escola sem partido e o ensino de Sociologia no Brasil", vol. 6, n. 12, 2017

*Doutor em Sociologia pelo IESP/UERJ e Professor Adjunto de Sociologia do CAp-UERJ. Email: walaceuerj@yahoo.com.br.

** Mestre em Ciências Sociais pelo PPCIS/UERJ e Professor de Sociologia do IFRJ (Campus São João de Meriti). E-mail: afilho30@gmail.com.
} 


\section{INTRODUÇÃO}

A projeção pública da organização Escola sem Partido (ESP) exige estudos, reflexões e debates acerca dos danos que sua efetivação legal pode provocar em todo o projeto pedagógico que se pretenda democrático e emancipatório.

Ao falar do ESP precisamos considerar tanto as forças que constituem o seu movimento quanto as propostas de lei que o representam. Existem inúmeros projetos que tramitam na Câmara, no Senado e em diversas casas legislativas pelo país, de modo que integram um pacote de contrarreformas juntamente com o projeto de lei de reforma do Ensino Médio (PL 746/2016) e com a PEC 55/2016 (ex-PEC 241).

É nesse sentido que o ESP deve ser lido sob a perspectiva conservadora que se difunde pelo país, fruto de um contexto de acirramento político marcado pelo crescimento de uma vertente autoritária que emergiu nos últimos anos e em especial após o impeachment de 2016.

A episteme por trás do programa retrata a mercadologização ampliada das relações sociais mais primárias, lógica que não poupa sequer a educação dos tentáculos do consumo. O ESP idealiza uma escola reduzida às relações do capital na qual a relação escola-professor-aluno fica restrita ao nexo mercantil.

\section{MOVIMENTO, SEUS PROJETOS E AS INCIDÊNCIAS PELO BRASIL}

Criado em 2004, o ESP apresenta-se como uma iniciativa conjunta de estudantes e pais preocupados com o que chamaram de "grau de contaminação político-ideológica das escolas brasileiras". A centralidade de suas ações e concepções está num site $^{1}$ que atua com os objetivos de veicular ideias, instrumentalizar denúncias, disseminar procedimentos de vigilância, além de controlar e criminalizar o que seus membros entendem como "práticas doutrinárias" realizadas em salas de aula e presentes em materiais escolares e acadêmicos, livros

\footnotetext{
${ }^{1}$ Ver: <http://www.programaescolasempartido.org/>. Acesso em: 30 ago. 2018.
} 
didáticos e programas formativos. O ESP também concentra forças nas redes sociais, tendo no Facebook ${ }^{2}$ uma página com os mesmos propósitos.

O fundador do movimento é o advogado e procurador do Estado de São Paulo Miguel Nagib, que se declara publicamente em nome da organização. Nagib, por sua vez, foi articulista e doador do Instituto Millenum (Imil), um dos mais representativos think-thanks do pensamento liberal brasileiro, o que nos revela a orientação ideológica que marca o começo do ESP e que influencia muitas de suas manifestações (ESPINOSA; QUEIROZ, 2017).

É curioso perceber que no site há um rótulo com o nome "ESP nas eleições 2016", onde se podem encontrar políticos apoiadores do movimento. Parece contraditório que um projeto batizado como "sem partido" tenha apoio de políticos, logo, de partidos. Muitos deles, inclusive, têm realizado propostas baseadas no anteprojeto disposto no sítio do $\mathrm{ESP}^{3}$ nas casas legislativas onde atuam.

No plano federal há o PL 867/2015², que tramita na câmara, de autoria do deputado Izalci Lucas Ferreira (PSDB/DF); e o PLS 193/20165, que está no Senado, de autoria do senador Magno Malta (PR/ES). Ambos propõem a alteração da LDB 96 com a inserção dos aspectos defendidos pelo programa. Outro projeto de lei, mais severo e que foi retirado em abril de 2017, era o PL 1411/2015 do deputado federal Rogério Marinho (PSDB/RN), que tipificava o crime de assédio ideológico com pena de prisão aos professores "infratores"6.

Há uma relação próxima do ESP com a direita brasileira. A proposta foi apresentada pela primeira vez em forma de projeto de lei em 2014, no estado do Rio de Janeiro, pelo deputado Flávio Bolsonaro (PSL/RJ). A segunda vez, ainda nesse

2 Chamada Escola sem Partido e disponível no link: $<$ https://www.facebook.com/escolasempartidooficial/>. Acesso em: 30 ago. 2018.

3 Existem três anteprojetos no site, bem semelhantes, um federal, outro estadual e o terceiro municipal.

4 Todos os trâmites do projeto, assim como o texto original, podem ser acessados no portal da Federal no link: <http://www.camara.gov.br/proposicoesWeb/fichadetramitacao?idProposicao=1050668>. Acesso em: 29 ago. 2018.

${ }^{5} \mathrm{O}$ texto do projeto pode ser lido portal do Senado Federal, onde o leitor também pode manifestar a opinião através de um voto. Ver em: <https://www12.senado.leg.br/ecidadania/visualizacaomateria?id=125666>. Acesso em: 29 ago. 2018.

6 Ver em: <http://www.camara.gov.br/proposicoesWeb/prop_mostrarintegra?codteor=1330054>. Acesso em: 29 ago. 2018. 
ano, foi no município do Rio de Janeiro, pelo vereador Carlos Bolsonaro (PSC/RJ), ambos filhos do deputado federal Jair Bolsonaro (PSL/RJ).

Abaixo um gráfico que indica a incidência de propostas de lei segundo os diferentes partidos, confirmando a tendência à direita. Os partidos que mais apresentaram projetos do tipo em câmaras municipais e estaduais pelo país em 2017 foram PP (Partido Progressista) e PSC (Partido Social Cristão), seguidos de perto por PSDB (Partido da Social Democracia Brasileira) e MDB (Movimento Democrático do Brasil, ex-PMDB).

Figura 1 - Os partidos do "Escola sem Partido"

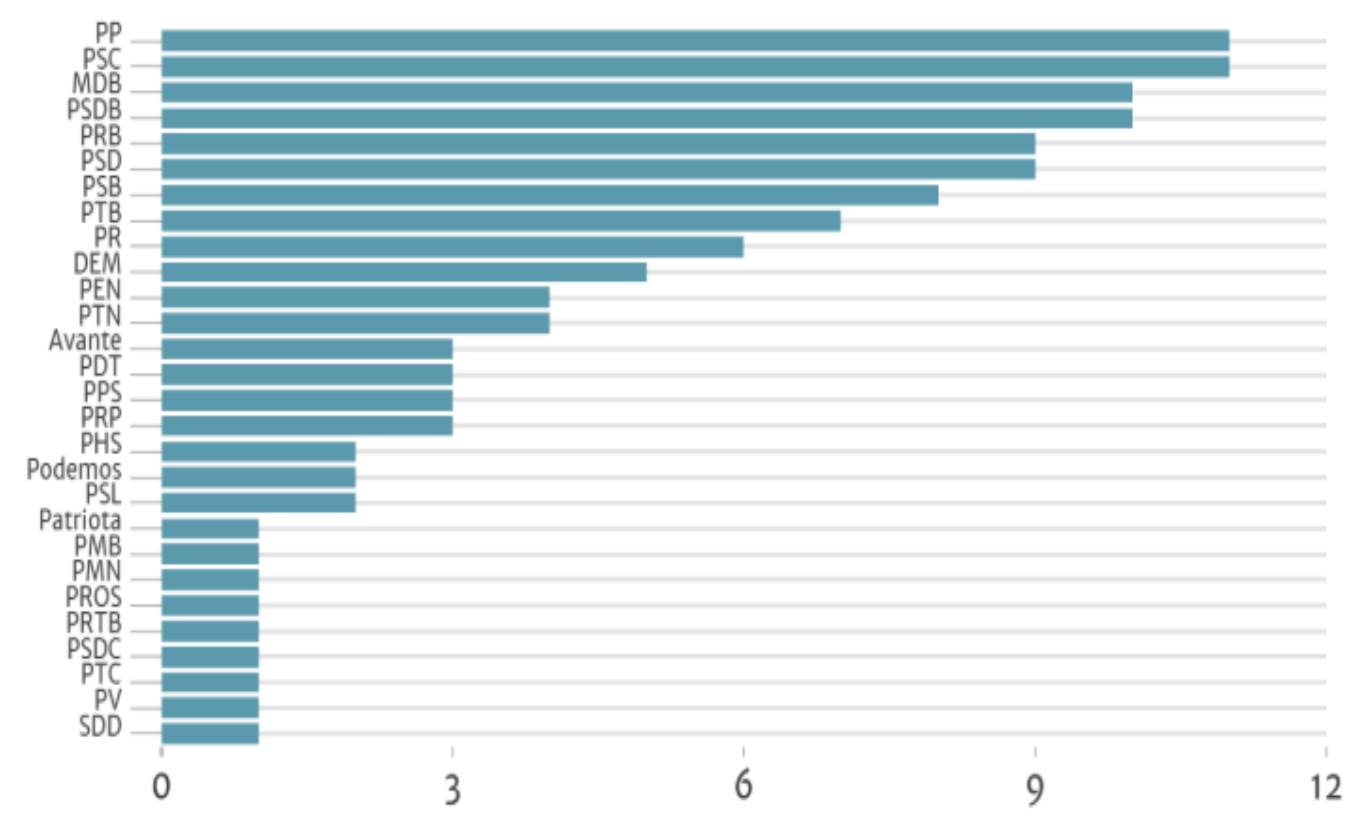

Fonte: Levantamento da Gênero e Número

Fonte: <http://www.generonumero.media/pp-psc-psdb-e-mdb-os-partidos-da-escola-sem-partido/>. Acesso em: 30 ago. 2018.

Existe também um vínculo do movimento com a bancada evangélica de diversas esferas legislativas, especialmente pelo fato de o programa combater a discussão de gênero e a diversidade religiosa nas escolas. Na câmara federal, por exemplo, a comissão especial que analisa a proposta, criada em 2016, é composta pela bancada evangélica. 
Bastos (2018) salienta que a pauta inicial do ESP soa distante da maioria das pessoas, o que teria levado a inclusão da pauta do combate à ideologia de gênero para provocar um pânico moral. É o medo que as famílias têm de seus filhos se transformarem em gays e lésbicas que faz com que o projeto ganhe visibilidade e consequentemente uma capilaridade de destaque pelo país.

Com objetivo de abordar essa proposta o ESP atua por meio da intimidação aos professores. Conforme apontado por Penna (2016), o MEC circulou um cartaz em 2016 com os seguintes dizeres: “Professor@, ninguém pode lhe impedir de discutir gênero/sexualidade na escola. Se for intimidad@, denuncie: Central de Atendimento Ministério da Educação 0800-616161/ secadi@mec.gov.br". Miguel Nagib divulgou o comunicado do MEC de seguinte maneira no seu perfil público no Facebook:

\section{Figura 2 - Divulgação de Miguel Nagib sobre comunicado do MEC em seu Facebook}

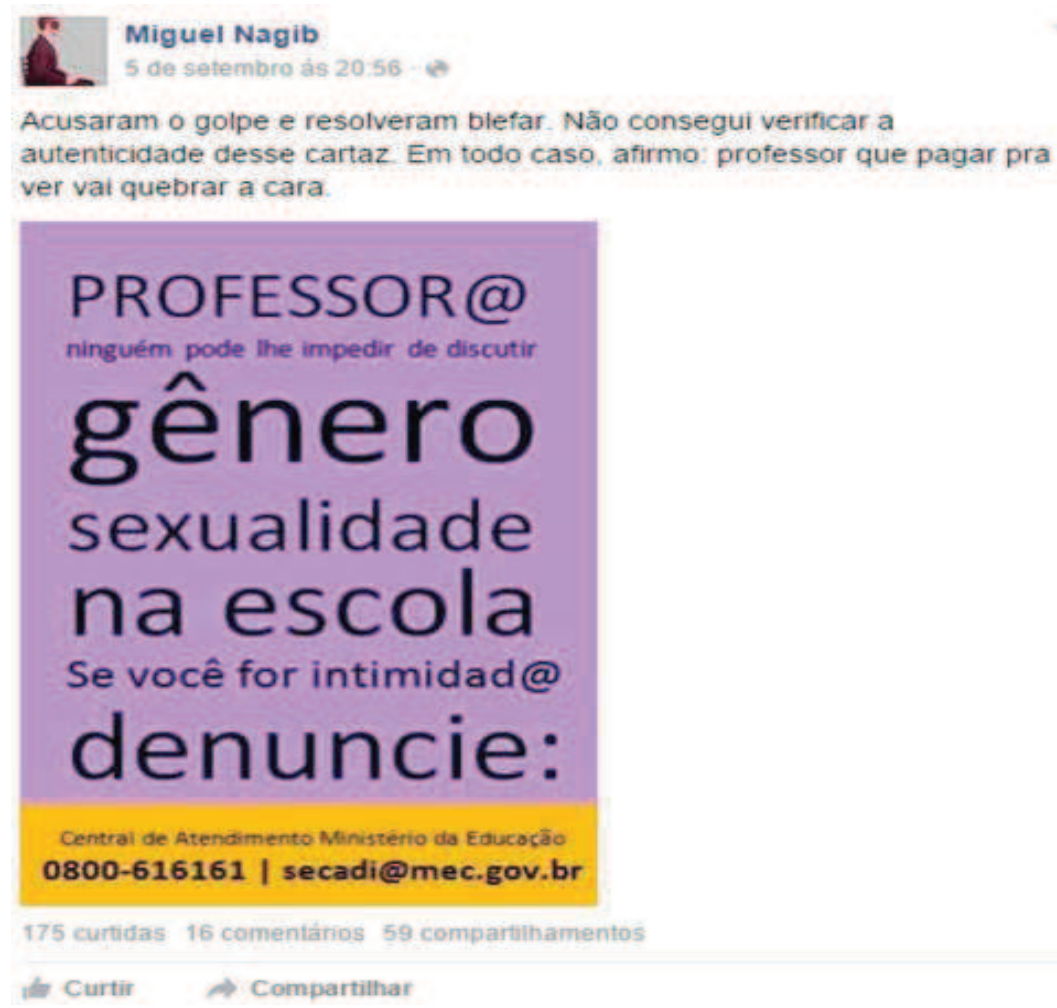

Fonte: <https://professorescontraoescolasempartido.wordpress.com/2016/11/14/o-odio-aosprofessores-se-profissionaliza/>. Acesso em: 15 set. 2018. 
O programa chegou a virar lei temporariamente em Alagoas sob o título de "Lei da Escola Livre". No texto promulgado, consta a determinação pela neutralidade de professores, prevendo punição a quem manifestar opinião que induza ao pensamento único de alunos em sala de aula. Todavia, a versão aprovada na Assembleia Legislativa alagoana foi parar no Supremo Tribunal Federal (STF) em uma Ação Direta de Inconstitucionalidade (ADIN) movida pela Confederação Nacional dos Trabalhadores em Estabelecimentos de Ensino (CONTEE). Ao se manifestar, a Advocacia-Geral da União (AGU) classificou o projeto como inconstitucional, alegando que legisla sobre uma área de competência da União, e também porque infringe o artigo 206 da Constituição, que garante a pluralidade de ideias no ambiente de ensino.

Em abril de 2017, o ministro Luís Roberto Barroso, do STF, concedeu liminar que a suspendeu na íntegra. Na decisão, Barroso destacou que a lei "é tão vaga e genérica que pode se prestar à finalidade inversa: a imposição ideológica e a perseguição dos que dela divergem. Portanto, a lei impugnada limita direitos e valores protegidos constitucionalmente (...)" (STF NOTÍCIAS, 2017). Com a decisão, o Escola Livre fica invalidado até o julgamento em definitivo pelo pleno do tribunal.

Já em cidades como Campo Grande (MS) e Picuí (PB) o Escola sem Partido foi aprovado, porém vetado após intensos protestos de movimentos de professores. Já em Santa Cruz do Monte Castelo, norte do Paraná, onde o programa virou lei e está em vigor, a rede primária do município passou a ter escolas tomadas por cartazes com os seguintes dizeres: "O professor não pode se aproveitar dos alunos para promover seus próprios interesses ou preferências ideológicas, religiosas, políticas e partidárias" (GOMES, 2016).

Em formato de projeto de lei, o ESP segue sendo debatido em pelo menos onze estados da federação e dezenas de municípios brasileiros ${ }^{7}$.

\footnotetext{
${ }^{7}$ Os projetos podem ser consultados no seguinte link: <https://pesquisandooesp.wordpress.com/plsmunicipios-e-estados/>. Acesso em: 15 set. 2018.
} 


\title{
3 O CONTEXTO POLÍTICO-ECONÔMICO POR DETRÁS DO ESCOLA SEM PARTIDO
}

Devemos reconhecer que nenhum movimento social, nem projetos de lei que encampem suas ideias, podem ser dissociados do contexto em que se desenvolvem. É, nesse sentido, que o ESP deve ser lido à luz da perspectiva conservadora que se difunde pelo Brasil. Como salientado por Frigotto (2017):

\begin{abstract}
As teses do Escola sem Partido não podem ser entendidas nelas mesmas e nem como algo que afeta apenas a escola e os educadores. Pelo contrário, um olhar na perceptiva da historicidade dos fatos e fenômenos, vale dizer, das determinações mais profundas e menos visíveis que os constituem, indica-nos que se trata de algo já sedimentado nas relações sociais (FRIGOTTO, 2017, p. 18).
\end{abstract}

O movimento está ligado a uma agenda multifacetada de propostas políticas que impede o acesso da juventude brasileira não apenas a frações do conhecimento, mas ao próprio conhecimento e ao fazer científico, seja pela intenção de incentivar o impedimento formal da abordagem de determinadas questões no âmbito pedagógico, seja pela falta de oferta curricular que privilegia determinados saberes em detrimento de outros.

A Proposta de Emenda Constitucional 241, apelidada de "PEC do Teto dos Gastos", que virou lei, acaba com a vinculação obrigatória de recursos para a educação e a saúde pública e inviabiliza o aumento de financiamento educacional necessário para a implementação das metas do Plano Nacional de Educação ${ }^{8}$, lei 13.005, aprovada em junho de 2014 após debate público e participação popular. Sendo um instrumento de planejamento orientado à execução e ao aprimoramento de políticas públicas do setor ente 2014 e 2024, a restrição orçamentária representa um imenso obstáculo na sua execução, ainda mais considerando que os recursos atualmente disponíveis para a educação pública já são insuficientes para garantir um padrão de qualidade que cumpra o previsto na legislação e para enfrentar as profundas desigualdades educacionais presentes no país (CARREIRA, 2016).

\footnotetext{
8 Disponível em: <http://www.observatoriodopne.org.br/uploads/reference/file/439/documentoreferencia.pdf $>$. Acesso em: 15 set. 2018.
} 
Há também que considerarmos a proposta de ampliação da terceirização da atividade fim (PL 4330/2004), que, na educação, abrirá caminho para minar ainda mais a carreira docente, o que impactará fortemente na qualidade do serviço prestado à população.

Este combo é um ataque frontal ao ensino no país e tem sua gestação num parlamento cujas propostas têm sido sistematicamente reprovadas pela sociedade e por técnicos. É preciso deixar claro que a agenda com a qual estamos lidando vai de encontro aos interesses dos menos favorecidos social e economicamente e daqueles que fazem da vida um compromisso com estes interesses e com a emancipação societária por meio da educação.

Com efeito, a Reforma do Ensino Médio, sustentada num forte esquema de lobbys e propagandas, pode vir a atingir alguns dos objetivos propostos pelo movimento ESP. Segundo Vieira (2017), isso pode acontecer diante de algumas tendências que estamos assistindo. A primeira delas seria a retirada do peso de matérias que exigem uma abordagem crítico-reflexiva do currículo. A segunda reside no incentivo ao modelo de ensino tecnicista, que compreende a educação como formadora de mão-de-obra massiva, especializada e barata direcionada ao mercado de trabalho. A terceira, e mais dramática, está no reforço da reprodução das desigualdades estruturais que já orientam o modelo educacional brasileiro, uma vez que a educação espelha as desigualdades sociais do país ao mesmo tempo em que as reproduz ${ }^{9}$.

O contexto em que vivemos suscita o pensamento de Istán Mészáros (2002), que atribui a crise atual a um movimento universal que atinge todas as esferas da vida, além de se tratar de um problema agudo e destrutivo de uma série de direitos. Nesse sistema, cada vez mais irracional, temos assistido a redução da força do poder político dos Estados nacionais e a transferência do governo do mundo para os organismos internacionais.

O ESP aparece no cerne das mudanças culturais que fazem parte desse grande sistema voltado para o lucro. É nesse contexto em que, para os partidários

\footnotetext{
${ }^{9}$ Sobre a reforma do ensino médio, ver: FERREIRA, Walace; SANTANA, Diego Cavalcanti de. A reforma do ensino médio e o ensino de Sociologia. 2018.
} 
desse programa, a educação responde aos interesses do grande capital sob a aparência cívica do "Todos pela Educação" (FRIGOTTO, 2017).

\section{A DISTORÇÃO DE PRINCÍPIOS BASILARES DA EDUCAÇÃO}

Os defensores do ESP criticam a escola, os professores, algumas das referências teóricas utilizadas no campo da educação, os livros didáticos e colocam os alunos como vítimas de um processo "doutrinário". Para Fernando Penna (2016), um dos mobilizadores da luta dos professores contra o projeto ${ }^{10}$, esse trabalho de desqualificação não ocorre através de uma argumentação racional, mas por meio de uma série de ataques pessoais e de imagens, muitas delas caricaturas de profundo mau gosto, que representam o professor, a escola e seus pensadores como ameaças a crianças inocentes, mesmo que não haja qualquer dado substantivo que apoie essa generalização indevida. Um exemplo está na imagem abaixo, compartilhada pelo próprio ESP na sua página no Facebook. Nela, um professor, de camisa vermelha e estrela no peito ${ }^{11}$, "enfia pela guela" informações sobre gênero (representada pelo arco-íris - símbolo do movimento LGBT).

Figura 3 - Imagem publicada pelo ESP em sua página do Facebook

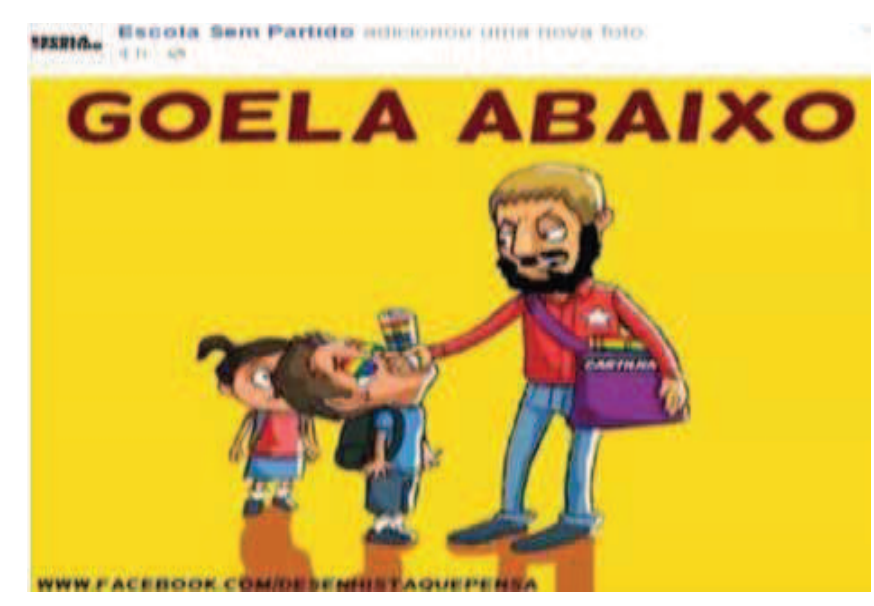

Fonte: <https://professorescontraoescolasempartido.wordpress.com/2016/11/14/o-odio-aosprofessores-se-profissionaliza/>. Acesso em: 15 set. 2018.

\footnotetext{
${ }^{10}$ Existe um grupo no Facebook que concentra notícias e mobilizações contra o movimento chamado "Professores contra o Escola sem Partido". Ver em: <https://www.facebook.com/contraoescolasempartido/>. Acesso em 15 set. 2018.

${ }_{11}$ Devemos lembrar que o Partido dos Trabalhadores (PT), mesmo não estando mais no governo federal, é, para os membros do ESP, o responsável por grande parte da ideologização presente na educação, sendo seus políticos alvo de manifestações de ódio e ofensas.
} 
Noutra imagem, postada como um comentário na mesma página, um homem mira uma arma de cano duplo na direção de quem olha. A mensagem ameaçadora demonstra o caráter agressivo do que chamam de "doutrinação" em torno da "ideologia de gênero", entendendo que a escola executa papel único na orientação de gênero do indivíduo, descartando tantas outras forças socializadoras do cotidiano.

Figura 4 - Imagem postada como comentário na página do ESP

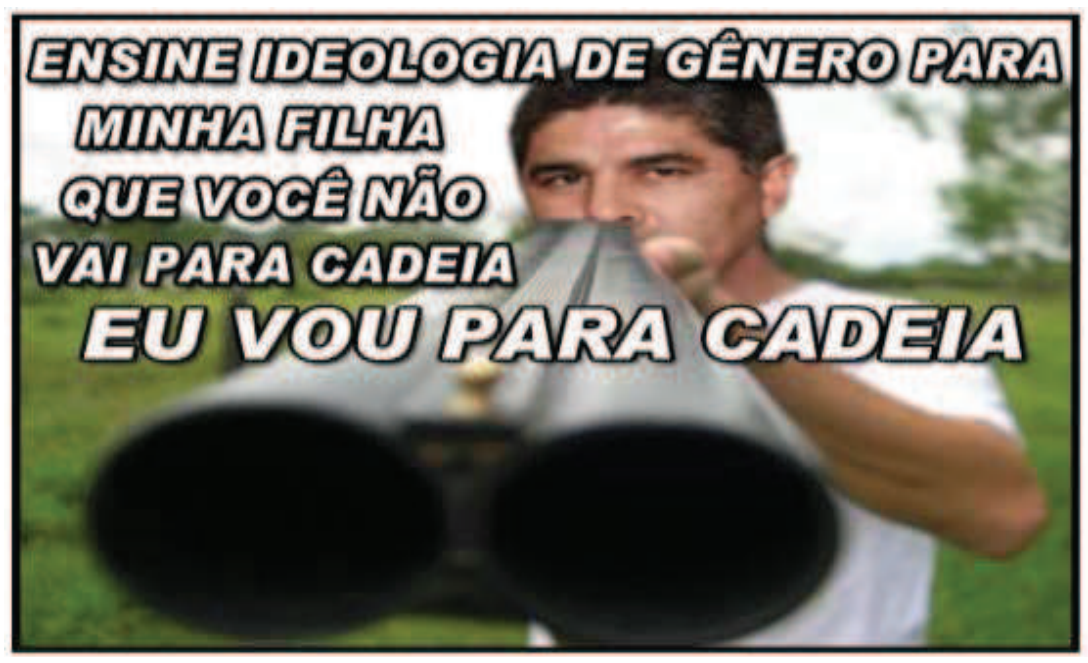

Fonte: <https://professorescontraoescolasempartido.wordpress.com/2016/11/14/o-odio-aosprofessores-se-profissionaliza/>. Acesso em: 15 set. 2018.

Naquilo que entendem como deveres do professor, seus defensores pregam que as salas de aula dos ensinos fundamental e médio devem ter o seguinte cartaz: 
Figura 5 - Deveres do professor segundo defensores do ESP Deveres do professor

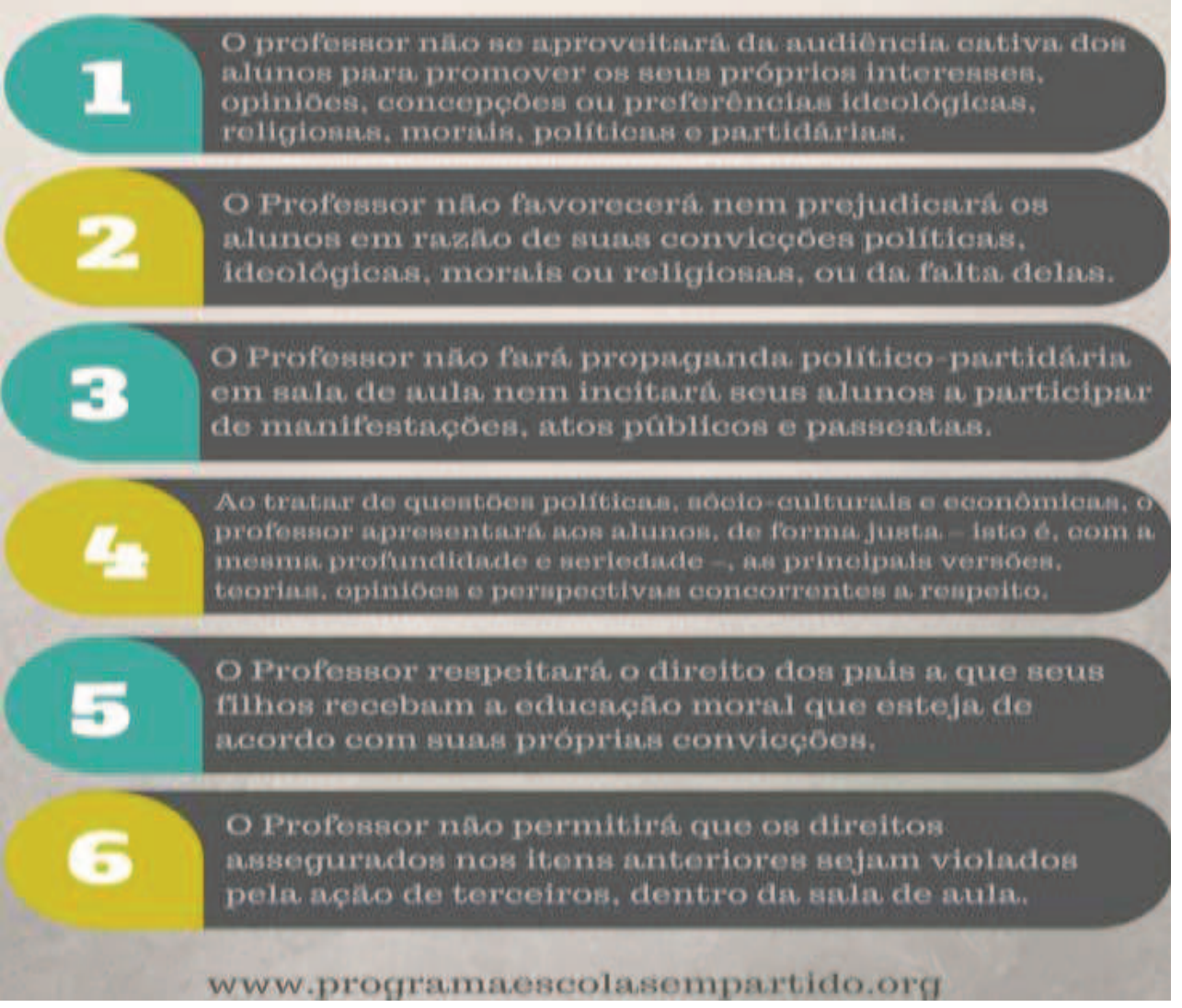

Fonte: < $\underline{w w w . e s c o l a s e m p a r t i d o . o r g}>$. Acesso em: 15 set. 2018.

A desconfiança em relação ao educador é um dos pilares do ESP e se traduz numa ameaça constante ao seu trabalho em sala de aula, entendendo-o como um tradutor "perigoso" do conhecimento diante de estudantes supostamente vulneráveis à chamada doutrinação. Diante da desconfiança com que vê o professor, ao participar de um debate na Globo News (2015), o fundador do movimento, Miguel Nagib, disse:

Nenhum pai é obrigado a confiar em um professor. Nenhum pai. O professor quando fecha a porta da sala de aula, ele é o dono do espetáculo. Se ele tiver uma boa formação e tiver bons princípios, sorte do aluno, mas e se não tiver? Como saber? Não é verdade? E há uma infinidade de pessoas que são mal preparadas e que cujos valores - eu nem entro no mérito se são bons ou ruins - mas que não coincidem com os valores da família (NAGIB, 2015). 
Diante dessa visão, o ESP estimula explicitamente o denuncismo, o controle, a insegurança e o cultivo a valores nocivos pedagogicamente que em nada contribuem para a construção de um ambiente saudável, de confiança e diálogo. Trata-se da aposta na instauração de uma ordem por meio de ameaças, da imposição do medo e da fertilização do discurso de ódio. Em vez da harmonia, coesão e produção de conhecimento, instiga alunos e pais ao papel de delatores. Há relatos substantivos de que professores têm sido denunciados e acusados de doutrinação em diversas salas de aula pelo Brasil, inclusive a partir de gravações de áudio e vídeo realizadas durante as aulas por estudantes com aparelhos celulares.

Ao acessar o site do movimento, assim como a página do Facebook, ficamos extremamente incomodados ao pensar no tipo de professor imaginado. Afinal, precisamos indagar que profissional de educação não estará pautando sua ação por preceitos morais e éticos. Não é preciso um projeto como este para nortear "eticamente" a atuação destes professores, que estão entre aqueles que mais trabalham e que têm as menores remunerações do mundo ${ }^{12}$, encarando enormes dificuldades para o desempenho digno de suas atividades.

Um professor não entra em uma sala de aula e ministra o conteúdo que melhor lhe apraz. As escolas seguem um currículo mínimo aprovado pelo Ministério da Educação e as aulas seguem cronogramas com o conteúdo destes currículos. As atividades pré-planejadas não são comícios políticos de recrutamento de militantes como alguns discursos querem fazer parecer.

O programa enxerga o aluno como uma tábula rasa, que chega ao espaço escolar imaculado de qualquer influência da vida social, como se o estudante não tivesse uma vida anterior, exterior e posterior à sua passagem pela escola. O ESP despreza a influência do espaço ocupado pelos meios de comunicação e pelas mídias diversas, hoje a serviço de valores eminentemente competitivos, consumistas e individualistas, com a qual toda a sociedade se relaciona diuturnamente.

Para Miguel Nagib, ademais, os professores estariam usurpando a autoridade moral dos pais, de modo que o movimento adotou como lemas

\footnotetext{
12 Pesquisa da OCDE que mostra essa realidade pode ser vista na seguinte matéria: <http://g1.globo.com/bom-dia-brasil/noticia/2016/09/professor-no-brasil-ganha-menos-e-trabalhamais-que-os-de-outros-paises.html>. Acesso em: 29 ago. 2018.
} 
“\#NãoMexamComAsNossasCrianças", "\#MeusFilhosMinhasRegras”, reduzindo os alunos quase a uma propriedade familiar (PENNA, 2017). Um exemplo disso aparece num diálogo entre Nagib e representantes do grupo Revoltados On Line, que apoia o ESP:

A segunda prática ilegal que também se disseminou no sistema educacional é a usurpação do direito dos pais dos alunos sobre a sua educação moral, da autoridade moral dos pais sobre os seus filhos. Também a máquina do Estado, o sistema educacional está sendo usado para isso, para afrontar a autoridade moral dos pais dos alunos sobre eles. E ai, a gente vê, por exemplo, a lei da palmada é uma consequência disso. Tiraram a autoridade dos pais, né, Miguel? Há um ataque frontal à família. (...) Nós já fizemos um slogan: 'Não mexam com as nossas crianças. Meus filhos, minhas regras' (NAGIB, Miguel; REVOLTADOS ON LINE, 2016) ${ }^{13}$.

Ao tocar na relação entre práticas educacionais e determinações definidas pelo Estado somos levados à conclusão de que política e educação não estão dissociadas. Como salientado por Freire (1999), a neutralidade é usada pela ideologia dominante para treinar os alunos para práticas apolíticas, como se a maneira humana de estar no mundo fosse ou pudesse ser uma maneira neutra. $A$ escola se constitui num espaço de formação onde o estudante deve aprender a analisar, comparar, avaliar, decidir, optar e romper. Como Ramos (2017) destacou:

A inseparabilidade (...) se manifesta no fato de o currículo escolar ser alvo de disputa de classes e um processo de seleção cultural e ideológica. O Escola sem Partido é a própria comprovação deste fato. Trata-se de tentar imprimir ao currículo escolar sua ideologia a qual, enunciada como neutra é, na verdade, totalmente comprometida com a classe dominante, pois impede que os interesses dos dominados sejam abordados na escola (RAMOS, 2017, p. 81-82).

Quem também questionou a ideia de neutralidade pregada pelo ESP foi o Ministério Público Federal, por meio do antigo Procurador Geral da República, Rodrigo Janot. No parecer de inconstitucionalidade do Projeto de Escola Livre, de Alagoas, o ex-chefe do MPF alegou que a lei suprime discursos fundamentais da

\footnotetext{
${ }^{13} \mathrm{O}$ vídeo foi gravado no mesmo dia em que o grupo, sem a presença de Nagib, se encontrou com o então Ministro interino da Educação, Mendonça Filho, em 25 de maio de 2016. Encontra-se disponível em: <https://www.youtube.com/watch?v=LpIMeRoMhWA>. Acesso em: 15 set. 2018.
} 
vida social ao proibir o docente de introduzir conteúdos que possam estar em conflito com as convicções morais, religiosas e ideológicas dos estudantes, seus pais e responsáveis:

A atividade de ensino não é via de mão única. Prevendo a lei que o aluno seria a "parte vulnerável" da relação de ensino, toma o processo de aprendizagem a partir da posição de autoridade exercida pelo professor e o compreende equivocadamente como atividade monológica e hierarquizada. Tomar o estudante como tabula rasa a ser preenchida unilateralmente com o conteúdo exposto pelo docente é rejeitar a dinâmica própria do processo de aprendizagem (BRASIL, 2016).

Além da descaracterização da essência da relação ensino-aprendizagem, esta ganha, para o ESP, tom absolutamente mercadológico. Nagib afirmou, em entrevista numa Audiência Pública no Senado Federal, em setembro de 2016, que o projeto ESP é baseado no Código de Defesa do Consumidor:

O nosso projeto foi inspirado no código de defesa do consumidor. $\mathrm{O}$ Código de Defesa do Consumidor intervém na relação entre fornecedores e consumidores para proteger a parte mais fraca, que é o consumidor, o tomador dos serviços que são prestados pelos fornecedores. Da mesma maneira, a nossa proposta intervém na relação de ensino-aprendizagem para proteger a parte mais fraca dessa relação que é o estudante, aquele indivíduo vulnerável, que está se desenvolvendo (NAGIB, 2016).

Portanto, uma tentativa de pensar a educação como uma relação de consumo, tirando-lhe seus valores nobres e reduzindo-a num mero produto negociável no capitalismo (PENNA, 2017).

\section{CONSIDERAÇÕES FINAIS}

Urge refletirmos acerca da base real sobre a qual este projeto se levanta. Se existe mesmo algum tipo de doutrinação nas escolas que tenha uma perspectiva marxista, revolucionária ou subversiva (isto para nos valermos de lugares comuns utilizados pelos advogados do projeto, que remontam os tempos de estado de exceção vividos no país entre 1964 e 1985), qual é a capacidade real que esta 
suposta doutrinação tem tido de atingir seus objetivos, que justifique um projeto contundente da envergadura do ESP?

Qual o percentual de egressos do Ensino Médio filiados a sindicatos, partidos políticos ou militando em organizações políticas? Onde estão estas pessoas que os organizadores de atos públicos não atingem seus objetivos de ocupar ruas ou grandes praças, exceto em atos unificados que congreguem várias categorias? Ao contrário, em geral, as adesões a greves convocadas pelos sindicatos são baixíssimas.

Talvez a energia mobilizada pelos partidários do ESP servisse melhor à sociedade se fosse canalizada para exigir uma educação de qualidade, pautada por um caráter público, gratuito, com estruturas adequadas a alunos e professores, salários dignos para todos os trabalhadores de estabelecimentos educacionais, oferta de alimentação balanceada, acesso a tecnologia de ponta e segurança.

A escola deve cultivar o compromisso com a ciência e com o desenvolvimento da técnica articulada com uma visão crítica de mundo, independente e laica, que respeite os Direitos Humanos, que contribua para a emancipação das minorias e que produza cidadãos conscientes e comprometidos com o bem estar comum. Uma educação que seja aliada do Homem comum e não sua adversária.

A escola tem um papel fundamental na sociedade, o de lidar com o projeto de mundo que será edificada para o porvir. O que se debate nas escolas tem correlação direta com o debate público e com a maneira como os indivíduos se relacionarão com a realidade. Um indivíduo dotado de habilidades e competências para manejar os preceitos da democracia e da cidadania transita melhor em ambientes marcados pela diversidade, contribuindo de forma determinante para a afirmação e para a ampliação de direitos.

Ainda que o projeto ESP não seja aprovado e seja definitivamente considerado inconstitucional, estando, portanto, impedido de se realizar formalmente dentro marcos da legalidade, é imprescindível atentarmos para o conjunto de valores que ele representa. Trata-se de enxergá-lo como a expressão de um campo conservador que assalta a sociedade e pretende transformá-la num celeiro monocromático de intolerância e autoritarismo. Sua força reside muito mais no que 
representa simbolicamente do que naquilo que terá capacidade de se converter formalmente.

\section{REFERÊNCIAS}

BASTOS, Mariana. PP, PSC, PSDB e MDB, os partidos da 'Escola sem Partido'. Revista Gênero e Número, [S.I.], 18 abr. 2018. Disponível em: $<$ http://www.generonumero.media/pp-psc-psdb-e-mdb-os-partidos-da-escola-sempartido/>. Acesso em: 30 ago. 2018.

BRASIL. Ações diretas de inconstitucionalidade 5.537/AL e 5.580/AL. Relator: Ministro Roberto Barroso. Disponível em: <http://www.mpf.mp.br/pgr/documentos/adi-5580-e-adi-5537-escola-livre.pdf>. Acesso em: 23 jul. 2017.

BRASIL. Medida provisória 746/2016. Disponível em: <https://www25.senado.leg.br/web/atividade/materias/-/materia/126992>. Acesso em: 15 set. 2018.

BRASIL. PEC 241/2016. Altera o Ato das Disposições Constitucionais Transitórias, para instituir o Novo Regime Fiscal. 2016. Disponível em:

<http://www.camara.gov.br/proposicoesWeb/fichadetramitacao?idProposicao=20883 51>. Acesso em: 15 set. 2018.

BRASIL. PEC 55/2016. Pec do Teto dos Gastos Públicos. 2016. Disponível em: <https://www25.senado.leg.br/web/atividade/materias/-/materia/127337>. Acesso em: 15 set. 2018.

BRASIL. PL 1411/2015. Tipifica o crime de Assédio Ideológico e dá outras providências. 2015. Disponível em:

<http://www.camara.gov.br/proposicoesWeb/fichadetramitacao?idProposicao=12298 08>. Acesso em: 15 set. 2018.

BRASIL. PL 4330/2004. Dispõe sobre o contrato de prestação de serviço a terceiros e as relações de trabalho dele decorrentes. 2004. Disponível em:

$<$ http://www.camara.gov.br/proposicoesWeb/fichadetramitacao?idProposicao=26784 1>. Acesso em: 15 set. 2018.

BRASIL. PL 867/2015. Inclui, entre as diretrizes e bases da educação nacional, o "Programa Escola sem Partido". 2015. Disponível em:

$<$ http://www.camara.gov.br/proposicoesWeb/fichadetramitacao?idProposicao=10506 68>. Acesso em: 15 set. 2018.

BRASIL. PLS 193/2016. Inclui entre as diretrizes e bases da educação nacional, de que trata a Lei n 9.394, de 20 de dezembro de 1996, o "Programa Escola sem 
Partido". 2016. Disponível em:

<https://www25.senado.leg.br/web/atividade/materias/>. Acesso em: 15 set. 2018.

CARREIRA, Denise. No chão da escola: Conversando com famílias e profissionais da educação sobre o Escola sem Partido. In: AÇÃO EDUCATIVA ASSESSORIA, PESQUISA E INFORMAÇÃO (Org.). A ideologia do movimento Escola Sem Partido: 20 autores desmontam o discurso. São Paulo: AÇÃO EDUCATIVA, 2016.

ESPINOSA, Betty R. Solano; QUEIROZ, Felipe B. Campanuci. Breve análise sobe as redes do Escola sem Partido. In: FRIGOTTO, Gaudêncio (Org.). Escola "sem" partido: esfinge que ameaça a educação e a sociedade brasileira. Rio de Janeiro: UERJ, LPP, 2017.

FERREIRA, Walace; SANTANA, Diego Cavalcanti de. A reforma do ensino médio e o ensino de Sociologia. Revista Perspectiva Sociológica, [S.I], n. 21, 2018, p. 4153, 2018. Disponível em:

<http://cp2.g12.br/ojs/index.php/PS/article/view/1740/1248>. Acesso em: 15 set. 2018.

FERREIRA, Walace; ALVADIA FILHO, Alberto. A serpente pedagógica: O projeto Escola sem partido e o ensino de Sociologia no Brasil. e-Mosaicos, [S.I.], v. 6, n. 12, 2017. Disponível em: <http://www.e-publicacoes.uerj.br/index.php/emosaicos/article/view/30272/21433>. Acesso em: 15 set. 2018.

FREIRE, Paulo. Pedagogia do oprimido. 26. ed. Rio de Janeiro: Paz e Terra, 1999.

FRIGOTTO, Gaudêncio. A gênese das teses do Escola sem Partido: esfinge e ovo de serpente que ameaçam a sociedade e a educação. In: FRIGOTTO, Gaudêncio (Org.). Escola "sem" partido: esfinge que ameaça a educação e a sociedade brasileira. Rio de Janeiro: UERJ, LPP, 2017.

GOMES, Karina. O único município que adotou o "Escola sem Partido". Portal DW, [S.I.], 08 set. 2016. Disponível em: <http://www.dw.com/pt-br/o-\%C3\%BAnicomunic\%C3\%ADpio-que-adotou-o-escola-sem-partido/a-19500841>. Acesso em: 29 ago. 2018.

MÉSZÁROS, István. Para além do capital. São Paulo: Boitempo, 2002.

NAGIB, Miguel. Audiência Pública para debater a liberdade de expressão na sala de aula. Youtube, 01 set. 2016. Disponível em:

<https://www.youtube.com/watch?v=jwGErV-1zUo>. Acesso em: 30 ago. 2018.

NAGIB, Miguel. Debate sobre sexualidade na grade de ensino escola. Entre Aspas (Mônica Waldvogel), 11 jun. 2015. Disponível em:

<https://www.youtube.com/watch?v=iNSC1rNOz74>. Acesso em: 30 ago. 2018. 
PENNA, Fernando de Araujo. O Escola sem Partido como chave de leitura do fenômeno educacional. In: FRIGOTTO, Gaudêncio (Org.). Escola "sem" partido: esfinge que ameaça a educação e a sociedade brasileira. Rio de Janeiro: UERJ, LPP, 2017.

PENNA, Fernando de Araujo. O ódio aos professores se profissionaliza.

Professores contra o escola sem partido, [S.I], 14 nov. 2016. Disponível em: $<$ https://professorescontraoescolasempartido.wordpress.com/2016/11/14/o-odio-aosprofessores-se-profissionaliza/>. Acesso em: 30 ago. 2018.

RAMOS, Marise Nogueira. Escola sem Parido: a criminalização do trabalho pedagógico. In: FRIGOTTO, Gaudêncio (Org.). Escola "sem" partido: esfinge que ameaça a educação e a sociedade brasileira. Rio de Janeiro: UERJ, LPP, 2017.

STF NOTÍCIAS. Suspensa lei alagoana que instituiu o programa Escola Livre. 22 mar. 2017. Disponível em:

<http://www.stf.jus.br/portal/cms/verNoticiaDetalhe.asp?idConteudo=338884\&caixaB usca=N>. Acesso em: 29 ago. 2018.

VIEIRA, Rafael Barros. Para uma crítica do Projeto de Lei 193/2016, que inclui na LDB o Programa 'Escola sem Partido'. Junho Blog, [S.I.], 01 abr. 2017. Disponível em: <http://blogjunho.com.br/para-uma-critica-do-projeto-de-lei-1932016-que-incluina-ldb-o-programa-escola-sem-partido/>. Acesso em: 28 ago. 2018. 